\title{
Strategy Control Model for Sustainable Manufacturing through Rural Development
}

\author{
Haishang $\mathrm{Wu}$ \\ Sunderland University, UK
}

\section{$\underline{\text { Summary }}$}

Additive manufacturing (AM) has been the core area of sustainable manufacturing commonly recognized for its high efficiency in enabling cost-effective production towards sustainability. There are three models this research constituted: In Collection-Recycling-Manufacturing (CRM) model, technologies and processes are benchmarked followed by Business model that evaluates industrial key criteria. However, these are insufficient for AM to effectively play dominant role as the realization requires human factors such as multi-entities authorities, policy making and AM society to initiate and execute the plan.

Strategy control model focuses on human-centric approaches such as demography, population control, policy, regulations, and management. It investigates each nation's demography, and enables strategy, plan and control to relocate overcrowding population to rural areas. It also produces robust workforce to support AM and materials recycling through the appropriate applications. Through the construction of AM and materials recycling, strategy control model creates job opportunities for those unemployed people. It further builds infrastructure for the livelihood of new residents and supports AM home-based business (HBB).

\section{Introduction}

Sustainability has been a crucial and complex topic in recent decades which focus on meeting the needs of the present without compromising the ability of future generations to meet their needs (Shah, M. 2008). Sustainability is composed of three key disciplines; economies, environment and society which correlate to each other's (Strange, T., Bayley, A., 2008). Materials recycling and sustainable manufacturing have been a vital subject to the sustainability as reusing materials protects environment from contamination and pollution, and materials recovery and saving have close link to all these key factors. Furthermore, they contribute economies and support a harmonious society. This research aims sustainable manufacturing through materials recycling and AM. A close-loop recycling and manufacturing means "From Cradle to Cradle" and "Zero Waste". It enables circular economies, protects environment ecosystem, and promote social well-being.

Materials recycling and AM has involved in complex processes and multi-disciplines which requires strategy to realize the plan and workforce to streamline the processes. Among all key elements, urban and rural population balancing can be decisive factor to drive the plan. Particularly in the recent few decades, polarization of urban-rural population and gap of the income between both areas has become serious problems threatening sustainability. 


\section{Literature Review}

Tremendous literature has been reviewed in terms of driving forces of people flow as well as the required workforce in recycling and AM. The current situation threats a normal progress of sustainable manufacturing. Migration from rural to urban areas has created problems in these few decades that impacts ecosystem, economies and society. Among all, migration caused by poverty can be the most significant issue to the sustainability; as such, UN Human Settlements Program advised segregation of rural areas requires critical review as they belong to a harmonious continuum. Ad hoc labor sourcing may satisfy timely demands but left problems behind as evidence shows that global rural population ratio dropped from $65 \%$ to $45 \%$ in two decades without notable benefit instead, it ruined rural development, damaged economies, broke ecological balance, produced vagrants and slums, and increased crime.

Existing literatures viewed urbanization a shortcut of economies and interpreted rural values as ad hoc sourcing from rural to urban particularly in the labor market. They may satisfy timely demands but left problems behind as it broke ecological balance, increased criminal records, and destructed sustainable economies. They followed secular trend, segregated linkage, inverted the values, and damaged livelihoods. In addition, lack of strategy has resulted in an unbalanced situation, missing of principles and guidelines further prevent genuine governance from sustainability.

Furthermore, government and authorities of communities shall be cautious about the rural ecosystem which should be protected for sustainable development and service delivery (Gebrea, T., Gebremedhinb, B., 2019). As a consequence, overcrowding has been a major issue degrading level of sustainability. According to The World Bank, $55 \%$ of population are in cities, and will reach $70 \%$ by 2050 . Due to rapid urbanization, $60 \%$ of displaced people are living in urban areas (The World Bank, 2020) and the vicious circle will be sustained.

Rapid population growth in metropolitans threaten environment against rural development, industrialization, natural habitats and causes environmental degrade. It has resulted in rapid growth of energy production and consumption. The environmental effects like ground and surface water contamination; air pollution and global warming are of growing concern owing to increasing consumption levels (Ray, I., 2011). Meanwhile, unbalanced urban-rural population and segregation has created tremendous poverties that highly impacts global economies, environment and society. For this reason, Multidimensional Poverty Index (MPI) which is composed of three equally-weighted dimensions (health, education and standard of living) is commonly used in the measurement of rural living quality. According to the MPI, $85 \%$ of multidimensional poor people hopelessly live in rural areas (Alkire, S., et al. 2014).

Consolidation of overcrowding population and low MPI residents in rural areas can form a powerful workforce in supporting sustainable manufacturing. Under strategy control model, a well-established demography contributes human factors to recycling and AM manufacturing and promotes their positions in industry mainstream.

Policy makers need multi-dimensional views to control demographic sustainability and to rationalize population in a most flexible way. Demographic sustainability is defined by the type and the size of the local 'dependency ratio' in order to ensure a multi-age structure and generational continuity of rural settlements in the national periphery. For instance, Israel settling authorities are looking to update the rural development 
policy to apply strategy control to rationalize its demographic sustainability. A GIS-based spatial search and mapping procedure was developed to identify and map the settlements in rank order of intervening needs in population policy. The strategy is focusing around three pivots: accelerators, limitations, and opportunities. Accelerators are the main reason for policy update and include the individual levels of demographic sustainability and relative free absorption capacity of each settlement. (Stern, E., 2013).

\section{Strategic Planning and Metrics Control}

This research proposes a framework which covers the collection-recycling-manufacturing (CRM) model, business model and strategy control model. CRM model is a bottom-up approach which focuses on technical benchmarking and process. Through CRM model, business model aggregates the assessment results into industrial evaluation and applications. However, these are not sufficient for sustainable manufacturing to stretch out its impacts and to play crucial role as many dependencies rely on human-centric investigation such as policy, regulations and workforce. Hence, strategy control model is proposed in this study, to investigate and supplement human factors in sustainable manufacturing.

\section{Three criteria of top-down approach}

Sustainability cannot be reached by one stroke particularly in the core area of the sustainable manufacturing. It relies on some human factors to initiate strategic analysis and apply control metrics to regulate the operations. For instance; population balancing, facilities allocation in rural areas and the relocation support of new habitants require plan and decisions. Strategy control model aims to fill-in the gap, promote rural industrialization, and create job opportunities and ultimate labour force in manufacturing sustainability.

In this top-down approach, strategy control model is responsible for three major criteria;

1) Rural Population Ratio (RPR) Analysis and its impacts to Rural Development

2) Top-300 cities Crowdedness Index (TCI) Resolution and its impacts to Job Opportunities

3) $\mathrm{AM}$ and recycling facilities allocation, Relocation Supports, and infrastructures implementation

Strategic control refers to the governance of demography, job allocation and infrastructure planning, so various industrialization plans can be implemented in rural or suburb areas. It is expected to attract workers by offering job opportunities in recycling and AM, and to establish their livelihood in rural areas. The realization of strategy control model will enable circular economies, protect environment ecology, and eliminate society outbreaks caused by vagrants, which can be three birds with one stone win-win case.

Both government and authority of communities have responsibility to initiate this top-down approach as it supports the establishment of sustainability in recycling and manufacturing under planned strategy. The economies developed through industrialization in rural areas will attract more migrants to devote the new life in recycling and AM that contributes sustainability of economies and environment. Meanwhile, metric control aligns the newly created recycling and manufacturing facilities to the targeted geographical locations and allocates new migrants based on the rationalized demography. As many unemployed people are offered to new opportunities in the rural or suburb areas, vagrants diminished, and criminal records eliminated that strengthen a sustainable society. 


\section{Discussions}

Strategy of TCI and RPR setting, control metrics threshold, job opportunities, rural development, utilities and new habitants' allocation, and infrastructure implementation are the key areas of discussion.

\section{IV-1. RPR Analysis and its impacts to Rural Development}

Rural population refers to the population of people living in rural areas as defined by national statistical offices. The sum of rural population divide by total population is RPR.

\section{Definitions of Rural, Urban and RPR}

First, the terminologies being used in rural demography theory are defined by World Bank as followed;

- Rural and urban: Any area whose population $>50,000$ inhabitants with a density of $>1,500$ persons/sqkm is urban. Any land area of one sqkm whose population is under 300 habitats is regarded as rural area.

- RPR: Rural population ratio is the sum of population in rural areas divide by total population of a nation.

- Population Density (PD): Population of a nation divides by total land area of that nation.

- Gross Domestic Product (GDP) per capita represents individual income. Low GDP means GDP $<$ \$10,000

- GDP growth rate: the average of yearly growth rate of GDP compared to previous year.

A sample of the top-ranking nations of Environmental Performance Index (EPI) score are listed as below. The nations of high EPI score usually have high GDP and low RPR. As indicated in Table 1, RPR can be key impact factor of GDP and EPI. GDP and EPI of 200 countries were computed and plotted against RPR.

\begin{tabular}{l|c|c|c|c}
\hline \multicolumn{1}{c|}{ Country } & RPR (\%) & GDP(\$) & GDP growth (\%) & EPI score \\
\hline Denmark & 12 & 60170.3 & 14.5 & 82.5 \\
\hline Luxembourg & 8.8 & 114704.6 & 26.7 & 82.3 \\
\hline Switzerland & 26.2 & 81993.7 & 16.3 & 81.5 \\
\hline United Kingdom & 16.3 & 42330.1 & 14.4 & 81.3 \\
\hline France & 19.3 & 40493.9 & 10.9 & 80 \\
\hline Austria & 41.5 & 50137.7 & 11.8 & 79.6 \\
\hline Finland & 14.6 & 48782.8 & 4.3 & 78.9 \\
\hline Sweden & 12.3 & 51615 & 20.4 & 78.7 \\
\hline Norway & 17.4 & 75419.6 & 13.5 & 77.7 \\
\hline Germany & 22.6 & 46445.2 & 13.6 & 77.2 \\
\hline Netherlands & 8.1 & 52331.3 & 7.4 & 75.3 \\
\hline Japan & 8.3 & 40246.9 & 27.9 & 74.9 \\
\hline Australia & 13.9 & 55060.3 & 6.8 & 74.3 \\
\hline Spain & 19.4 & 29600.4 & 13.8 & 73.3 \\
\hline Belgium & 2 & 46420.7 & 57.9 & 72.8 \\
\hline Ireland & 36.6 & 78661 & 20.8 & 72.3 \\
\hline Iceland & 6.1 & 66944.8 & 11.5 & 72 \\
\hline Slovenia & 45.2 & 25946.2 & 28.7 & 71.3 \\
\hline New Zealand & 13.4 & 42084.4 & 18.8 & 71 \\
\hline Canada & 18.5 & 46194.7 & & \\
\hline
\end{tabular}

Table 1. Sample scoring of RPR, EPI and GDP 


\section{RPR Effeteness}

As indicated in figure 1-a, the plotting of RPR against PD; most of the nations of high PD have low RPR due to saturated population and limited land area and Singapore can be a typical example. When RPR is higher than $10 \%$, the RPR values are independent of PD as the nation has sufficient buffer to absorb saturated population. Figure 1-b demonstrates the interference between EPI and RPR. Usually lower RPR can affect EPI and indirectly impact economies. However urbanization is inevitable to those nations with strong economies background, may compensate the loss by raising the EPI funding and still achieve high EPI score. The trend reflects that EPI score declines with increasing RPR however, when RPR is lower than 10\%, EPI score can drop depending on how the nation handle the optimization between economies and environment factors. The other critical factors are; when EPI-RPR correlation is classified by GDP factor with a value of $\$ 10,000$ that divide GDP into high and low; the EPI stays high even under a 50\% of high RPR value. This effect exists in both groups that when RPR $<10 \%$, EPI drop. For high GDP group, when RPR $>10 \%$, there is no correlation between RPR and EPI. However, higher RPR still affects EPI in those low GDP nations.
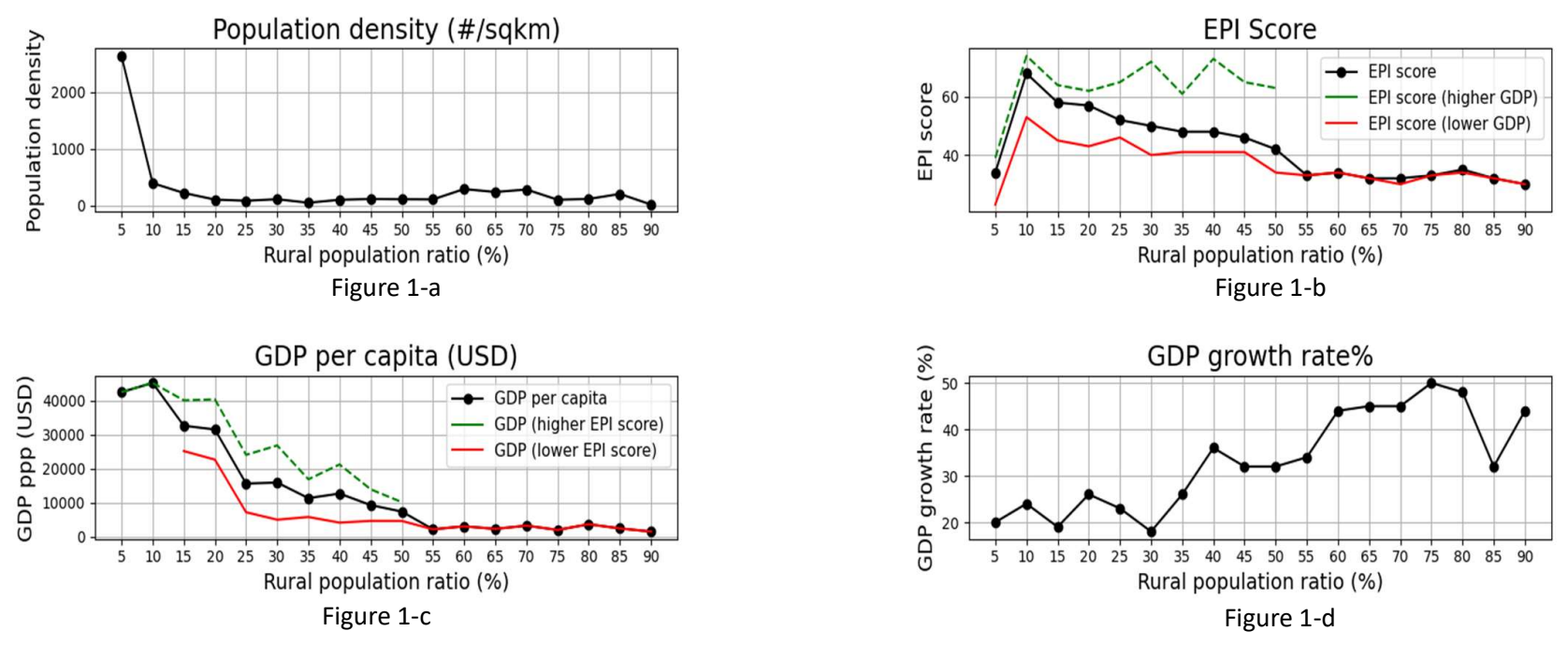

Figure 1. RPR vs. Density, EPI, GDP and GDP growth

Figure 2-c indicates GDP against RPR to demonstrate the trend among 200 nations. It reflects the fact that higher RPR will not favor GDP however; lower RPR of less than 10\% value will not contribute GDP which need be avoided for those nations with strong economies background. Figure 2-d further explains the correlation between GDP growth rate and RPR. Particularly to those developing countries; low RPR usually affect GDP growth rate which shall be avoided for those developing countries.

RPR analysis exploits raw data from World Bank database in 3 decades (1987-2017) and the correlations to key factors such as EPI, GDP, and GDO growth rate can generate critical indicators for demography control and infrastructure planning. In a fixed rural area, increase of RPR means mobility of habitants from urban to rural areas. Through rural development, job opportunities can be a genuine driving force to those over-saturated population. It supports unemployment in metropolitan and solves many issues from economies, environment 
and society perspectives. Through priority settings and dependencies analysis; RPR can be the decisive factor to regulate rural population. It aligns the rural development to manufacturing sustainability, and drive sustainable development into a virtuous cycle.

\section{Strategy of the RPR Control}

The metrics such as GDP, EPI and RPR change fast, therefore, dynamic control and flexibility can be critical to deploy strategy control model to effectively impact sustainability. Much of the governmental regulations are lack of agility and adhered to outdated policies make fractional enhancement difficult to compensate the loss from the whole. Misalignment between the policy-makers and the executions of civil society can be other issue affects the control (McCauley, D., 2008).

Furthermore, a genuine principle of governance is required to ensure the consistency of decision-making, effective regulations and equitable guidelines (Biermann, F. et al., 2014), so the prioritized steps can serve as an integrated skeleton to drive the whole. In general, the strategy of rationalization of RPR is outlined as followed;

- Threshold settings: The RPR, derived from optimization process, suggests threshold control which can better achieve a green level for both GDP and EPI. From empirical statistics, each nation has its threshold, which provides a better chance to commit sustainability for all economies, environment and society. Once the key factors are defined, the threshold can be derived as control metrics. RPR control is the key of measurement which can be the control metrics of sustainable development.

- Established cases: To those well-established and developed countries with sound economies background; try to avoid RPR value lower than $10 \%$ to retain certain level of sustainability. Relocating surplus habitants in urban to rural areas is the priority and it shall target those unemployed workers, vagrants, slum-stayers, or people who enjoy rural life. Recycling and manufacturing in rural areas achieve sustainability in economies, environment and society; hence government and authorities shall facilitate sufficient infrastructure and same quality of livelihood as in urban areas to support new habitants' relocation.

- Developing cases: To those developing and lower GDP nations; rural development can be a critical factor in achieving sustainability. Urbanization contributes GDP, but over-urbanization can affect RPR value and block rural areas from performing its expected functions. For this reason, the government and associated authorities shall avoid falling into the same trap instead; they shall focus on rural development through industrialization. In the other word, government shall plan recycling and manufacturing industry in rural areas as first priority. Once the rural industrialization foundation is built and GDP growth rate become steady, an optimized solution of RPR range of 10-35\% contribute both GDP and EPI towards sustainability.

- Job Opportunities: Based on this approach, government and authorities create job opportunities according to the topology of hub-like industrial centres and build infrastructure. It facilitates new habitants' livelihood at hubs surroundings to develop collaboration between HBB and Small to Medium Enterprise (SME). 
- Facility Planning: Based on the guidelines of recycling and manufacturing topology, this research plans the facilities and plants, and aligns the appropriate manpower to the planned locations of the recycling facilities to form industrial centres and AM society.

- Infrastructure: Infrastructure describes all plants and facilities that are sufficient to provide habitants' livelihood to develop sustainability in the place of their settlement. In principle, this research proposes the same quality and equal opportunity of accessibility to public infrastructure for both rural and urban areas. Infrastructure covers facilities for livelihood and industrialization; the hub-like topologies and connections shall be planned ahead, so the strategy can add values to infrastructure through industrialization.

- Collaboration: To establish a concrete foundation of local manufacturing and local supply, this research proposes hub-like centres in those recycling facility surroundings (i.e; manufacturing recycling facilities), and construct manufacturing plants nearby the centres to guide SME and HBB practitioners to establish their 3D-Printing business.

\section{Rural Development}

This study investigates the causes that affect rural demographic distribution impacting rural development. It applies threshold and control metrics to rationalize and support new habitants to relocate to the targeted areas. However, poverty can be one of the main barriers that blocks rural development.

Sociologists (Chowdhury et al, 2012) (Hussain et al, 2014) indicated that poverty has been the critical cause of rural to urban migration, and alerted surplus labor destruct balance in an uncontrolled system accelerate unemployment rate of lower-income labor, potentially leading to criminal cases and outbreaks.

Poverty in rural area has caused rural to urban migration which affect rural development. Strategy control model rationalizes demography and applies the raw data, provided by World Bank and EPI, to analyze 200 nations' statistics. Eventually it produces guidelines of rural demographical control. The model proposes the justified rural demography that ultimate sustainability through optimization between economies, environment and society.

To avoid repeating mistakes, strategic control first applies the empirical statistics to produce metrics for demographic threshold settings followed by rural development plan. The plan covers the demographic distribution of each location and the statistics of plastic waste. It also covers the capacities of recycling and manufacturing estimation that to be allocated to each location. In addition, the associated authorities create job opportunities in each targeted location, and start to recruit targeted groups of people to initiate relocation plan followed by education and training.

Rural development, through recycling and manufacturing, creates job opportunities which resolve economies, environment and society towards sustainability. To realize the goal, industrialization plays critical role in rural development. Global agriculture sector has maintained as low as 4\% in recent two decades but still supplied sufficient foods to ever-increasing population implies the existing scale and farming technologies can satisfy basic demands and the values decayed from excess foods according to Keynesian model. For this reason, industrialization in surplus rural areas can be critical to economies. 
From the other side; with the advent of industries and effective land usage, sustainability can be the objective as economies, society, and environment correlates under certain conditions and supports each other's (Patnaik, R., 2018).

In addition to industrialization, infrastructure planning can be the other key factors (Alcorta, L., 2015) of realization. It describes facilities and the necessary service such as education, technology, energy, construction, transportation, communication, job centre, culture, healthcare and other utilities that support habitants' livelihood. Infrastructure planning shall be launched based on RPR and collaboration, to take care of rural habitants' services. It also instructs industrialization in plants and buildings construction, and equality of infrastructure and services access to rural areas support sustainability and help the planning of future development (Serrat, O, 2017). Eventually, infrastructure planning can realize strategy control and support sustainable development.

By means of strategy control and planning in rural development, the three key disciplines can be optimized into one integrated process staring with the threshold settings to the metrics tuning. The RPR represents the ratio of total population of areas being defined as rural areas. The experiments of this research demonstrate correlative regression between economies and environment which implies both factors can establish a mutually beneficial effect should the ratio is well controlled under a specific range. Meanwhile, the collaboration supports healthy society under a well-tuned RPR as the rationalization of RPR eliminates vagrants and outbreaks and collaboration enhance rural resilience in sustainability.

\section{IV-2. Crowdedness (TCI) Definition, Resolutions and Job Opportunities}

TCI is the other key factor that link to sustainable development in rural areas. There is a general guideline for the threshold setting however; the tuning of the TCI threshold is case by case as each country has different conditions and plan.

\section{Crowdedness (TCI) and Density:}

City Mayors (City Mayors Statistics, 2018) provides a list of global 300 major cities in terms of population and land areas. For each country, the summation of the population of all cities in top-300 list divide by the summation of their land area will derive TCI as a crowdedness indicator of that country.

Let $\mathbf{p}_{\mathbf{n}}$ be the population of $\mathrm{n}^{\text {th }}$ city of a nation

Let $\mathbf{a}_{\mathbf{n}}$ be the land area of $\mathrm{n}^{\text {th }}$ city of a nation

Let $\mathbf{d}_{\mathbf{n}}$ be the density of $\mathrm{n}^{\text {th }}$ city of a nation

Let $\mathbf{C}$ (TCI) be the crowdedness of a nation represented by $n$ cities

Let $\mathbf{P}$ be the population (residents count) of a nation

Let $\mathbf{A}$ be the land area (sq. km) of a nation

Let $\mathbf{D}$ be the density (people per sq. $\mathrm{km}$ ) of a nation (Worldbank, 2018)

Assume there are $\mathrm{n}$ cities in a country, and there are $\mathrm{m}$ cities in top-300 list.

$\mathbf{d}_{\mathrm{n}}=\frac{\mathbf{p}_{n}}{\mathbf{a}_{n}} \quad$ (density of a city) $\quad \mathbf{D}=\frac{\mathrm{P}}{\mathrm{A}}$ (density of a nation) $\quad \mathbf{C}=\frac{\sum_{m=1}^{m} \mathbf{p}_{m}}{\sum_{m=1}^{m} \mathbf{a}_{m}}$ (C: TCI of a nation) 


\section{Urbanization classification (L1, L2 and L3)}

According to European Commission (Dijkstra, L., 2020), definition of the degree of urbanization can be classified into three different levels; urban, suburb (or peri-urban), and rural, and the classification is based on the density (residents per sq. $\mathrm{km}$ ) and minimum population requirement. In addition, this study adds one more level (L0) on top of L1 which leveraged to TCI. Table 2 provides definitions of four urbanization levels.

\begin{tabular}{clcc} 
urbanization level & title & residents/sq. $\mathrm{km}$ & minimum population size \\
\hline \hline L0 & Top-300 cities & varied & none \\
L1 & Urban & $>1500$ & 50,000 \\
L2 & Suburb (peri-Urban) & $300-1,500$ & none \\
L3 & Rural & $<300$ & none
\end{tabular}

Table 2. Urbanization level definition

\section{Crowdedness resolution for rural development}

Overcrowding causes significant problems such as housing, air pollution, diseases, outbreak, congestion, unemployment, social problems and energy tension. The effective resolution is to rationalize demographic distribution and relocate residents of overcrowding cities to dilute the density.

There are two patterns of resolutions in solving overcrowding issues. As indicated in rural development session, job opportunity is the driving force of people flow. If labor market can drive poor people from rural to urban, then the same driving force can move people in reverse direction should they are offered a career in rural areas. Among all, job opportunities can be the tactical factor and source of driving force.

Sustainable AM manufacturing has committed great cost saving and will keep a $30.2 \%$ yearly growth, and reach $\$ 21.50$ billion by 2025 (Frost \& Sullivan's Global Research Team, 2016) that can create millions of job opportunities in rural or peri-suburb areas to move such relocation into reality.

Figure 2 demonstrates the three steps of each pattern, and considers priority in the transformation.

- Pattern A: Mitigate population in L1 (urban) first, then L0.

- Pattern B: Mitigate population in L0 first, then L1.

Among these two patterns, pattern B can be preferred option of demography rationalization. The reasons are; compared to L1, L0 overcrowding (step 1) is the priority need be resolved first, and step 2 is optional depends on severity of crowdedness and RPR level.

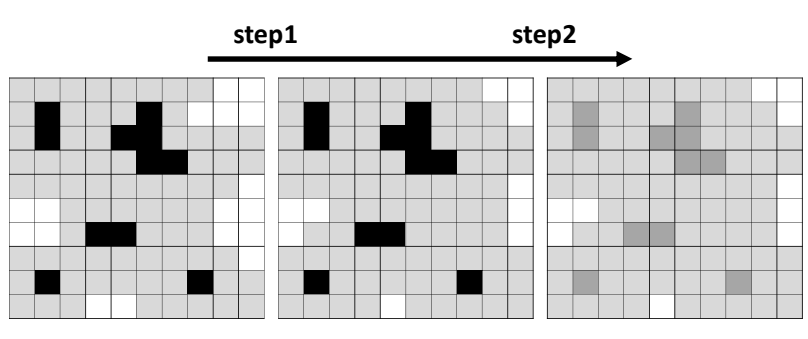

Pattern A: Rationalize RPR first and then Crowdedness

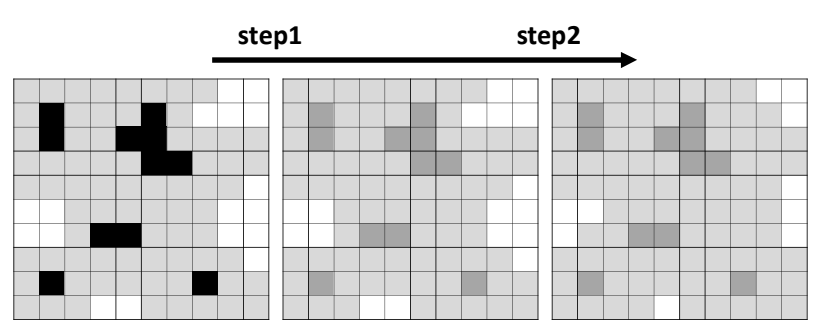

Pattern B: Rationalize Crowdedness first and then RPR 


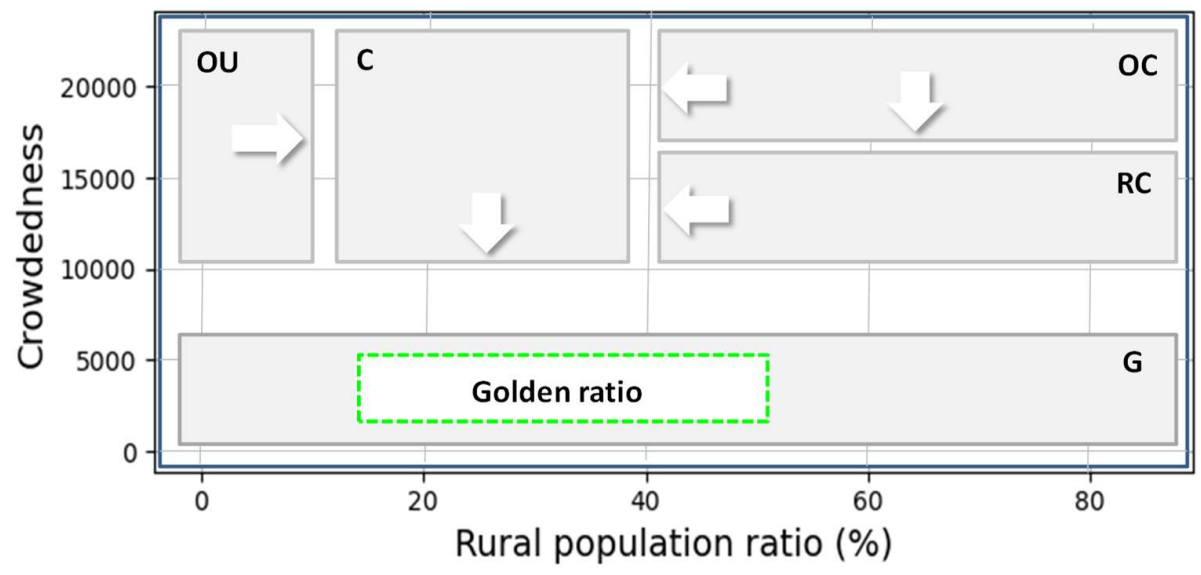

OU: over-urbanization

C: Crowded

OC: over crowded

RC: rural centric

G: green

Golden ratio: $15-50 \% \mathrm{RPR} /<5000 \mathrm{TCl}$

Figure 3. Patterns of RPR vs. TCI

\section{Strategy and Control of TCI, RPR and Density}

As indicated in figure 3, each country can have individual plotting between RPR and TCI mapping and the overall results can be categorized into five patterns; over-urbanization, crowded, overcrowded, rural-centric, and green. The arrow stands for control direction, and the golden ratio (RPR: $15-50 \%$ and TCI $<5000$ ) can be a reference model of threshold control. In refer to table 3, Japan falls in the marginal ' $G$ ' zone and 'OU' zone need an increase in RPR and step 1 in pattern B may solve the problem. Australia is a typical case that fully satisfies 'golden ratio'. Singapore is an 'OU' case, and due to high density of population, the country may find it difficult to increase RPR. India is a typical 'OC' case with serious polarization between overcrowding cities and rural areas. 'OC' need both step 1 and step 2 to apply spacious rural areas to absorb over-crowdedness. It is involved in both TCI and RPR factors and requires at least two steps to settle the issues.

\begin{tabular}{|c|c|c|c|c|c|c|c|}
\hline City / Urban area & Population & $\begin{array}{l}\text { Land area } \\
(\mathrm{sq} \mathrm{Km})\end{array}$ & $\begin{array}{c}\text { Density } \\
\text { (people per sqKm) }\end{array}$ & Country & $\begin{array}{c}\mathrm{TCI} \\
\text { (people per sqKm) }\end{array}$ & $\begin{array}{c}\mathbf{R P R}_{(\%)} \\
\text { RPR }\end{array}$ & $\begin{array}{l}\text { Country Density } \\
\text { (people per sqKm) }\end{array}$ \\
\hline Melbourne & $3,162,000$ & 2,080 & 1,500 & \multirow{5}{*}{ Australia } & \multirow{5}{*}{1446.8} & \multirow{5}{*}{14} & \multirow{5}{*}{3.35} \\
\hline Sydney & $3,502,000$ & 1,687 & 2,100 & & & & \\
\hline Brisbane & $1,508,000$ & 1,603 & 950 & & & & \\
\hline Perth & $1,177,000$ & 964 & 1,200 & & & & \\
\hline Adelaide & $1,002,000$ & 729 & 1,350 & & & & \\
\hline Delhi & $14,300,000$ & 1,295 & 11,050 & \multirow{6}{*}{ India } & \multirow{6}{*}{15100.2} & \multirow{6}{*}{66} & \multirow{6}{*}{468.66} \\
\hline Hyderabad & $5,300,000$ & 583 & 9,100 & & & & \\
\hline Bangalore & $5,400,000$ & 534 & 10,100 & & & & \\
\hline Kolkata & $12,700,000$ & 531 & 23,900 & & & & \\
\hline Mumbai & $14,350,000$ & 484 & 29,650 & & & & \\
\hline Chennai & $5,950,000$ & 414 & 14,350 & & & & \\
\hline Tokyo/Yokohama & $33,200,000$ & 6,993 & 4,750 & \multirow{5}{*}{ Japan } & \multirow{5}{*}{4693.8} & \multirow{5}{*}{8} & \multirow{5}{*}{345.82} \\
\hline Nagoya & $9,000,000$ & 2,875 & 3,150 & & & & \\
\hline Osaka/Kobe/Kyoto & $16,425,000$ & 2,564 & 6,400 & & & & \\
\hline Fukuoka & $2,150,000$ & 544 & 3,950 & & & & \\
\hline Sapporo & $2,075,000$ & 414 & 5,000 & & & & \\
\hline
\end{tabular}

Raw data: City Mayors Statistics

Table 3. Case studies of TCl, RPR and density 
The golden ratio threshold control is for generic usage and each nation may have individual thresholds of TCI and RPR once the control settings synchronize with strategic planning the country plan to achieve. However, a high deviation from the reference model can increase the risk and mitigation of TCI or RPR is required. Figure 4 highlights the criticality of such adjustment; for instance, Japan may consider reducing TCI or increasing RPR though these are not real issue. Comparatively, India may have urgency to reduce TCI and RPR, to move over-crowdedness from L0 to L1, L2 and even L3. Hence, the population distribution can be effectively resolved, and recycling and AM manufacturing can be allocated in L2 or L3 areas.

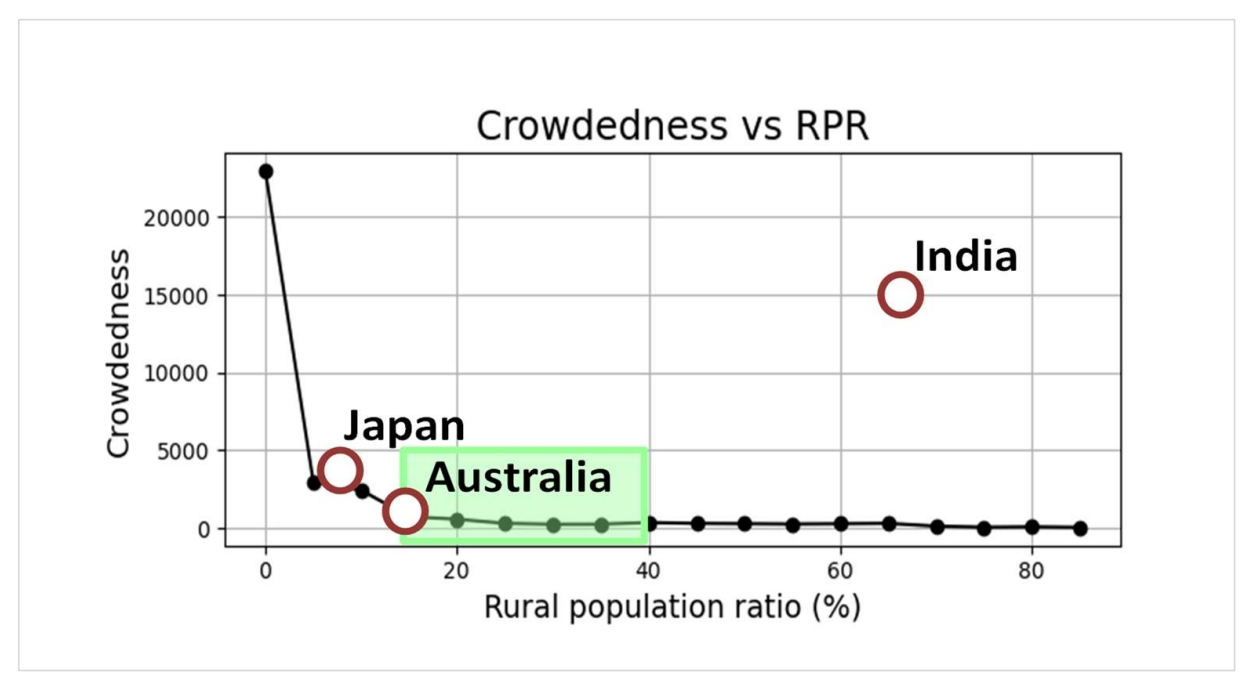

Figure 4. Sample of RPR and TCI threshold control

\section{Job Opportunities in rural or suburb areas}

In term of job opportunities; this study aims to create tremendous job vacancies through the construction of sustainable manufacturing facilities. It will relocate over-saturated population of high crowdedness to the areas nearby the facilities. Hence the new residents can start their new career or work as HBB. Allocating job opportunities to suburb or rural areas can be the driving force encouraging unemployment people to relocate. In contrary to service industry, AM manufacturing and materials recycling are not the industry suitable for urban areas, and migration from urban to rural or suburb can solve overcrowding issues and contribute sustainable manufacturing.

The economies developed through industrialization in rural areas can support funding of environmental sustainability and strengthen rural resilience. Furthermore, as many unemployed people have access to new opportunities, vagrants diminished, and criminal records eliminated. Due to the fact that both rural and urban habitants possess equal level of access to public infrastructure and social benefits, the newly created job opportunities supports a healthy society. It protects abnormal people flow and prevents unfair transaction.

The collaborative model supports healthy society under controllable thresholds of TCI and RPR. Eventually, the rationalized TCI eliminates vagrants and outbreaks and implementation of control metrics support collaboration contributes rural resilience in sustainability. 
Vagrant people create society problems in an overcrowded city and degrade environment quality as well. This research develops sustainability by means of strategic planning and control metrics through a virtuous cycle. Rural development and job opportunities are the main focus, and rural population, facilities construction and infrastructure implementation are key elements of driving force. As indicated in figure 5; through the realization of this study, sustainable manufacturing can be effectively implemented. Eventually, global poverty is expected to be eliminated from predicted $8.6 \%$ to $7.0 \%$, materials recycling and AM manufacturing are expected to keep on annual growing of $30-40 \%$, and natural resources and life quality are expected to be improved for a minimum of $30 \%$.

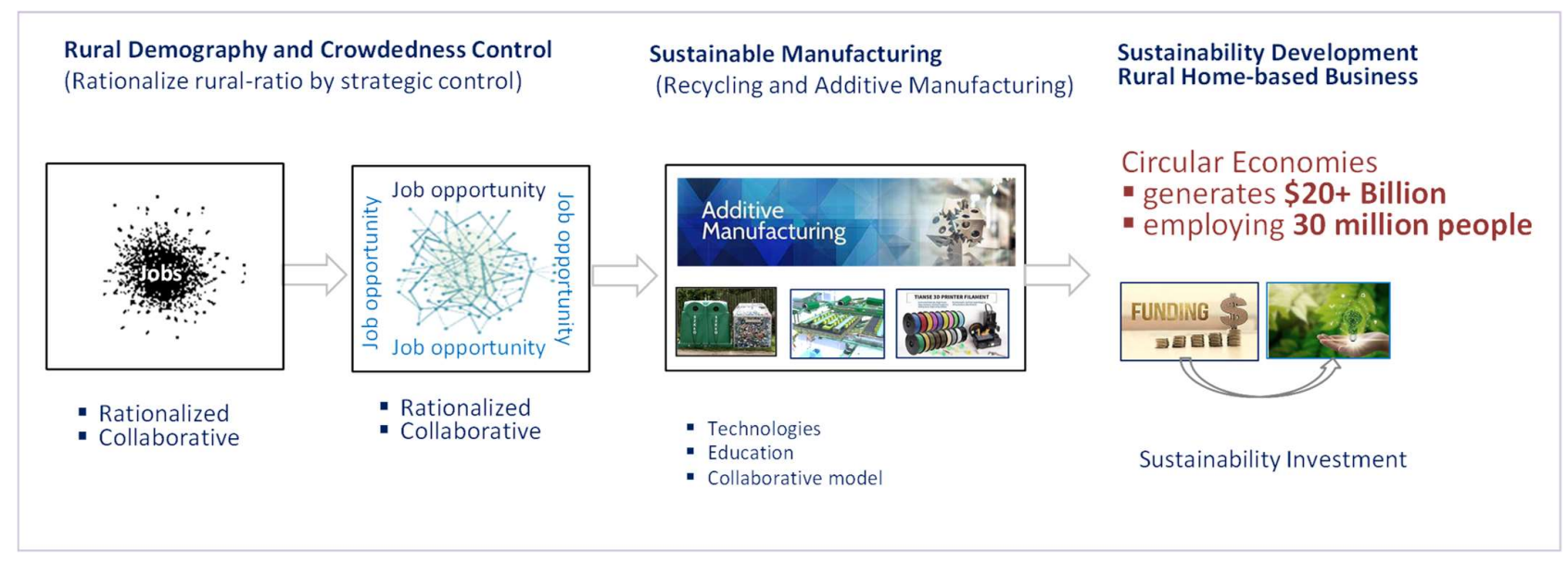

Figure 5. Job opportunities creation for recycling and AM manufacturing

\section{IV-3. AM and Recycling Facilities and Infrastructure Implementation}

$\mathrm{AM}$, or 3D printing for $\mathrm{HBB}$, plays crucial role as it redefine the design, manufacture and supply chain management in the modernization of recycling and manufacturing process. In this transformation, metrics of facilities and process evaluation, and supply chain management are introduced to assess the impacts.

The integration of AM and recycling facilities is complex which covers many different facilities such as collection, maintenance, disassembly, sorting, transportation, filtering, materials processing, manufacturing, and distribution. The process benchmarking is critical as the assessment provides critical factors to plan appropriate facilities at targeted locations. Details of the assessment are provided by the CRM model which can be applied to this study. Compared to new resin and conventional manufacturing (CM) process, materials recycling process can save materials up to $90 \%$. In addition, integration of recycling and AM process saves energy and $\mathrm{CO} 2$ emission up to $67 \%$ which can be the prioritized method for sustainable manufacturing.

\section{AM and recycling facilities}

The main facilities and processes in recycling processes consist of; collection sites (CS) such as kerbsides, civil amenity or other bring sites, data processing unit (DPU) to collect data for governance purpose, material recovery facility (MRF), waste transfer stations (TS), and final destinations (FD) of recycled materials. 
Among all combination of recycling and manufacturing options, integration of recycling and AM can effectively achieve sustainable manufacturing, zero supply chain, and circular economies. Due to the fact that 3D printing supply chains offers distributed manufacturing configurations minimizing downstream logistics (Cotteleer and Joyce, 2014), local manufacturing can be one of the reasons the AM manufacturing will become industry mainstream. Through networked production planning, scheduling and manufacturing execution functionality shall be established to underpin AM. This can be also the reason this study proposes materials recycling and AM manufacturing as a standard process. Under the strategy control model, the process can align TCI and RPR control metrics to ultimate the synthesis of AM advantages and AM community.

To support the AM transformation and fully utilize recycling facilities, a concrete foundation and roadmap is necessary. It is expected to guide the collaboration and corporative strategy, by taking step-by-step approach, to streamline the transformation. Geographically, recycling facilities, AM materials manufacturers and AM manufacturers shall be closely linked and the distance between these facilitators shall be as short as possible. This study also proposes hub-like AM society or industrial park to establish the strategy and to apply control metrics to realize the plan. To achieve the objectives, standardization of AM and recycling is critical as software specification and AM files format are the determinants in this evolution.

\section{Plastic Materials and Processes}

Materials recycling refer to MRF which is the critical gate within "Cradle-to-Cradle". Types of recycled materials vary, but filament can be a primary type of recycled materials locally supplying AM manufacturing. The process flow of waste collection, recycling and manufacturing is illustrated in figure 6 . In this end-to-end process, CS gathers all the sources of waste and start the sorting process. Through TS, the plastic waste is sorted and transferred to MRF for recycling. Among all plastic waste materials, PP and PET are the main plastic sources contributing over $45 \%$ of global production and over $60 \%$ of them are used in packaging industry (Yeo, J., et al, 2018). Both PP and PET plastic wastes are popular and easy recovery. For instance, PET, the most prevailing plastic in daily life being used in water bottles, is the most common plastic being recycled. In addition, HDPE is usually used in bleach type bottles can be sorted without any difficulty.

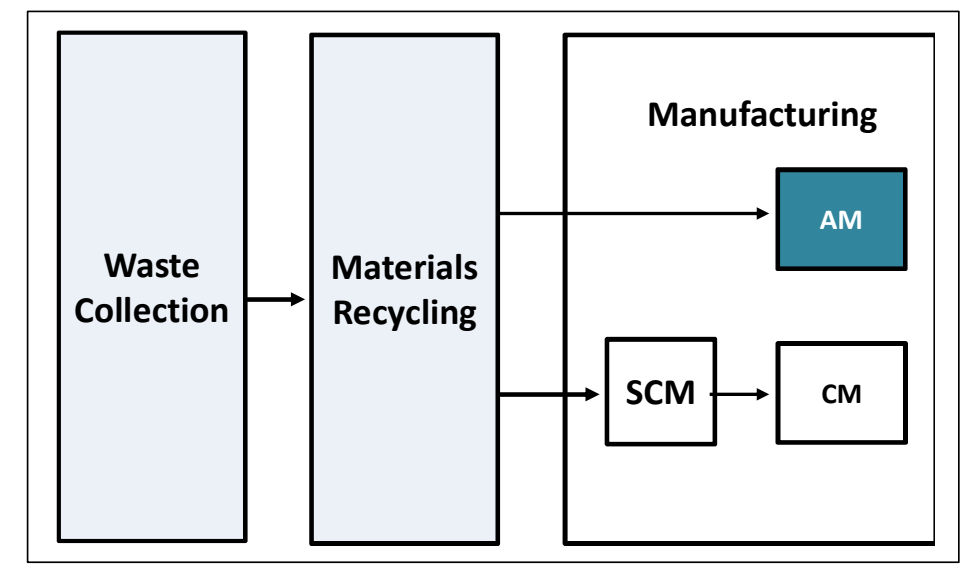

Figure 6. CRM process 
AM manufacturing, followed by collection and recycling, which doesn't rely on supply chain to distribute source materials, and this is an advantages over CM. In the whole process, the optimization of profit can be represented by the following generic form;

$\sum_{i=1}^{n} M_{i} \times p_{i}-\sum_{i=1}^{n} A_{i}-\sum_{i=1}^{n} M_{i} \times \sum_{j=1}^{m}\left(t_{i, j}+e_{i, j}\right) \times d_{i, j}$

$\boldsymbol{M}_{i}$ (ton): Materials at $\mathrm{i}^{\text {th }}$ site MRF ready for Recycling

$\boldsymbol{p}_{\boldsymbol{i}}$ (\$/ton): Profit factor

$\boldsymbol{A}_{\boldsymbol{i}}$ (\$/MRF): Amortization cost at $\mathrm{i}^{\text {th }}$ site MRF facility setup fee including land cost

$\boldsymbol{t}_{i, j}\left(\$ /\right.$ ton-km): unit cost of transportation for the original waste site $\mathrm{i}$ to travel from facility $\mathrm{j}-1$ to $\mathrm{j}$ at $\mathrm{i}^{\text {th }}$ site

$\boldsymbol{e}_{i, j}$ (ton/ton): $\mathbf{C O}_{2}$ emission (ton of $\mathbf{C O}_{2} /$ ton of materials) caused by transportation for the $\mathrm{i}^{\text {th }}$ site to travel from facility $\mathrm{j}-1$ to $\mathrm{j}$

$\boldsymbol{d}_{i, j}(\mathrm{~km})$ : distance $(\mathrm{km})$ from facility $\mathrm{j}-1$ to $\mathrm{j}$ at $\mathrm{i}^{\text {th }}$ MRF site (source to sink)

Among the key elements, $d_{i, j}$ is the decisive factor of transportation cost, energy consumption and $\mathbf{C O}_{2}$ emission. Hence, the MRF allocation shall not be far away from the sources of transportation. However, in consideration of the air pollution caused from recycling, MRF shall be allocated at suburb, the transportation distance between source and sink shall be optimized and a general guideline is $100 \mathrm{~km}$ or less will be suitable.

\section{Alignment between TCI, RPR and MRF allocation}

TCI and RPR control metrics provide critical information for MRF allocation as MRFs need be geographically allocated to areas with high population rather than an even distribution. The location of new migrants, also needs to be close to the location the MRFs are planned. There are two steps plan to drive the MRF allocation;

Step 1: Apply TCI and RPR threshold to rationalize population and plan new demography.

Plan the MRFs geographical allocation according to new demography.

Step 2: Fine tune the new residents' residing location according to the real location of facilities.

Implement infrastructure according to AM community with easy access to facilities.

The new demography is rationalized and ready for relocating people from over-crowdedness (L0) to L1, L2 or L3. The new demography plan also envisions MRFs allocation plan as indicated in figure 7. In the geographic representation of MRF infrastructure, some dramatic differences by region are particularly clear. Major population centers have an abundance of residential sorting facilities. In less population areas, however, have less or no MRFs. MRFs in United States can be a typical case as demonstrated in figure 8. (Staub, C., 2019).

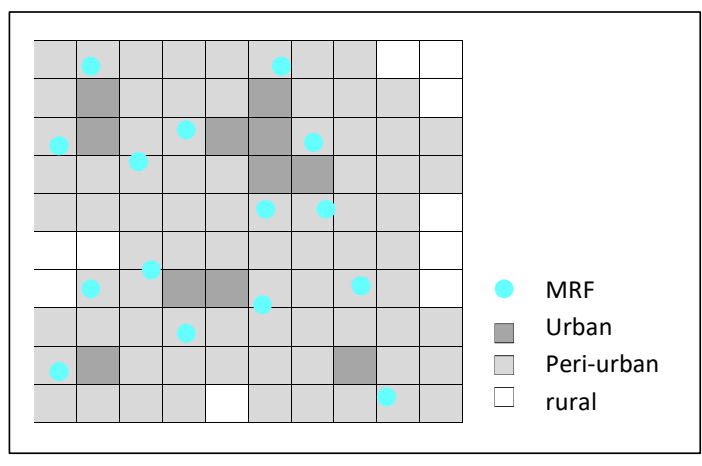

Figure 7. MRF allocation based on urbanization level

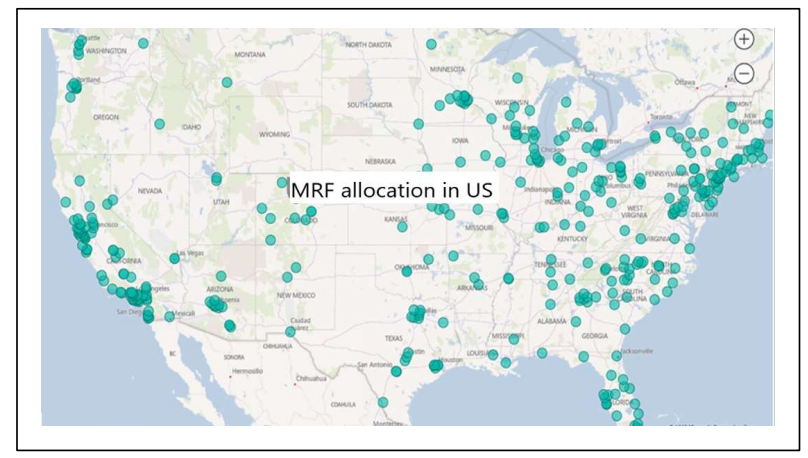

data source: Staub, C., Resource Recycling

Figure 8. MRF allocation in US as example 


\section{Supply chain reduction through Local Recycling and Local Manufacturing}

In general a supply chain consists of suppliers, manufactures, logistics, retail, consumers and recycling companies. When a centralized manufacture is transformed into distributed manufacture, SCM's position is changed from a cost driver into a value driver which implies the position of SCM has been shifted that sustain customers' satisfaction. A close connection between recycling and AM manufacturers can effectively realize strategic planning and metrics control as discussed in previous sessions. This also reduces supply chain dependencies in an agile end-to-end process. In recent years, SCM for 3D printing has been transformed into a service-based mediator that shortens the gap between materials supplier, manufacture and end-users. This transformation brings-in huge impacts and opportunities of customization in design, time-to-market, and flexibility in distribution. Figure 9 further illustrates the concept of hub-like collaboration between LE-SME$\mathrm{HBB}$, that realizer the plan of strategy control model. The new residents are expected to devote their new career in sustainable manufacturing, and their role can be the workers at LE or SME, and their families are expected to join AM community as HBB workers.

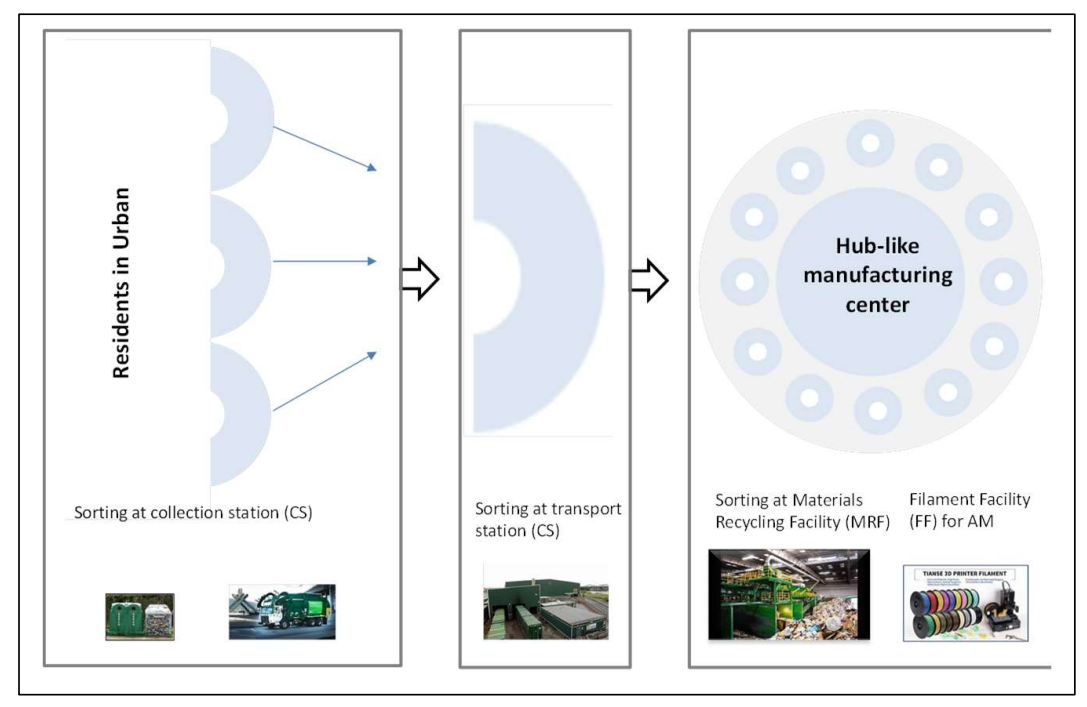

Figure 9. Facilities topology and hub-like collaboration pattern

\section{MRF construction}

AM community is the foundation of collaboration and physically it relies on a topology to establish the productivity. MRF can be the center of hub-like topology which is managed by LE. Within this topology, SME and HBB collaborate closely to ensure materials; machine and services are in place, so the massive HBB workers can contribute massive production in 3D printings.

A typical MRF can handle 200,000 tons/year of Plastic polymers. Most of the MRF can be enhanced to increase this capacity. Based on this assumption, MRF count of each country in the list is calculated according to the plastic consumption. The "estimated MRF" count is compared to the real "MRF count" each country is operating. Most of the countries have sufficient MRF to manage the plastic waste based on the current capacity however; several countries still have a gap to commit a full recycling of plastic waste. 
As illustrated in table 4, the plastic consumption of each country vary, India and China have less MRFs than estimated. This can be an issue in achieving "Zero waste" objective. Germany, Netherlands and Ireland consume high volume of plastics, need be reduced. Canada, Australia and Poland consume less and MRFs are very sufficient. (World Population Review, 2021)

\begin{tabular}{l|r|r|r|r|r} 
Country & Plastic waste (ton) & MRF estimated & MRF count & Population & Averaged (kg/person) \\
\hline China & 59079741 & 295 & 97 & 1444216107 & 40.9 \\
\hline US & 37825550 & 189 & 417 & 332915073 & 113.6 \\
\hline Germany & 14476561 & 72 & 286 & 83900473 & 172.5 \\
\hline Brazil & 11852055 & 59 & 102 & 213993437 & 55.4 \\
\hline Japan & 7993489 & 40 & 388 & 126050804 & 63.4 \\
\hline Russia & 5839685 & 29 & 285 & 145912025 & 40 \\
\hline UK & 4925580 & 25 & 331 & 68207116 & 72.2 \\
\hline Spain & 4709157 & 24 & 100 & 46745216 & 100.7 \\
\hline France & 4557128 & 23 & 234 & 6542617 & 69.7 \\
\hline India & 4493080 & 22 & 16 & 1393409038 & 3.2 \\
\hline Mexico & 3725463 & 19 & 27 & 130262216 & 28.6 \\
\hline Italy & 2899258 & 14 & 361 & 60367477 & 48 \\
\hline Netherlar & 2571398 & 13 & 70 & 17173099 & 149.7 \\
\hline Malaysia & 2031675 & 10 & 36 & 32778194 & 6.2 \\
\hline Poland & 1346905 & 7 & 175 & 37797005 & 35.6 \\
\hline Canada & 1154309 & 6 & 67 & 38067903 & 30.3 \\
\hline Portugal & 1022683 & 5 & 63 & 10167925 & 100.6 \\
\hline Australia & 900658 & 5 & 62 & 25788215 & 34.9 \\
\hline Ireland & 715716 & 4 & 29 & 4982907 & 143.6 \\
\hline Norway & 499682 & 2 & 33 & 5465630 & 91.4 \\
\hline Singapore & 359483 & 2 & 17 & 5896686 & 61 \\
raw data: World Population & Review & & & & \\
\hline
\end{tabular}

Table 4. MRF estimated and existing MRF count for sample nations

\section{Human factors case studies}

Strategy control model also cover areas of human factors that are not in the coverage of CRM and business modes. For instances, combined with manufacturers' awareness, customer behavior can be one of key factors in reducing waste from source. Prior to "Recycle" there are "Refuse" and "Reduce" that can be implemented through consumers, manufacturers and distributers. Consensus of "Reduce" is important, for examples; consumers may have good sense in waste reduction but have little control since most goods sold in stores are packed with layers of plastic. However, "Refuse" provides opportunity for customers to consume in more ecofriendly ways.

Meanwhile, culture can be a factor that affects environmental performance. For instance, in Japan it is culturally considered as polite to pack items in many layers. From the societal aspect, it does promote hygiene and the "omotenashi" (decent) service of proper care, but from economic and environmental perspective, it produces unnecessary cost and materials consumption. This can be one of the reasons Japan ranks top tier in the world in terms of plastic packaging waste per capita. Customers' attitude and response may help shift manufacturers' awareness, to create and sell more eco-friendly products. 
The other case study is regarding HBB practices. In Japan, a regular resident who has very limited knowledge of CAD, can manage production of 68 different types of small plastic items within a year, and the only assistance is a basic handbook. The items they produce are miniatures, such as stamps, mini-fans, augments such as prolonged parts of hanger, or amending parts of existing devices such as battery cases. Some of the items are customized for self-use, but some of them are for sale. From the viewpoint of sustainability, HBB fully utilize materials based on demands and create business opportunities as well.

In term of recycling culture, Eco Town Program (Kawasaki Eco-town, 2018) can be a typical case study of local recycling. The concept was origin from Kalundborg, Denmark. Since 1997, 26 regions were approved by government as of 2005. Being focus on recycling plastics and home electronics, the "Zero Emission" has been the objective of local revitalization. The concept is initialized by a plan, developed by cities, towns, or business unions, to get a signature from prefectural government. Governments of prefecture and cabinet designate cities then gain approval from the Ministry of the Environment (MoE) and the Ministry of Economy, Trade and Industry (METI), and then the community will receive support provided by the ministries. According to a brief calculation of MoE, the establishment of Eco Town led to reduction of 96,000 tons of final waste, and 46,000 tons of $\mathrm{CO}_{2}$ in 2011 across the 26 regions. The establishment also boosted economy, by drawing $\$ 1.70$ billion investment.

\section{Infrastructure construction}

AM is an emerging technologies widely spread across different regions and has been a dominant trend over the world. AM industry aims: "Started from small to become big" and the collaboration between HBB, SME and large enterprise (LE), play crucial role in AM transformation. A typical example is the collaboration between Wabtec Corporation and HP and launched an AM Center, focused on accelerating the design, standard, and production of integrated 3D-printed components in India. Wabtec Corporation-HP collaboration is one of successful stories of LE-SME-HBB collaboration (Chandavarkar, A., 2020) and particularly suitable for those large countries possessing high population, advanced technologies and massive labor force.

Realization of strategic planning and metrics control relies on a good foundation of infrastructure construction in peri-urban or rural areas to take care of residents' livelihood towards sustainability. From sustainable development viewpoint, rural residents deserve the same infrastructure and services to make it a resilient society (Shaw, R.,2019). In the infrastructure construction; education, training, job center, transportation, housing, Medicare, and communication are typical factors maintaining a quality living standard. Rural habitants, either newly relocated or existing residents are encouraged to join the collaboration to establish a mutually beneficial AM society.

Among all, educational action research is a key factor maintaining consensus and interoperability across multientities within designer, stakeholder, consumer, and distributers in end-to-end recycling process. First, people's concept needs a change as consumers need to understand the invisible values are hidden inside the waste. Recycling play key role in waste management as it recycles the value and protect environment. Second, the stakeholders need to be involved in the recycle process of their products, and build the recycling process to fabricate products through recycling route. The third, government need a tracking mechanism to reevaluate the waste collecting topology, the supply chain and connectivity between source channel and products channel. 


\section{Conclusions}

Materials recycling and AM manufacturing have close connection to demography and population distribution. This study suggests to allocate the recycling facilities and AM manufacturing to the location with minimum transportation distance while air pollution can be other factor need be considered. In general, the distance between source and sink of plastic waste shall be maintained within $100 \mathrm{~km}$.

This study proposes strategy control model aims to solve the polarization of urban-rural population and gap of the living standard between both areas. It rationalizes each nation's demography, and enables control metrics to relocate overcrowding population to rural or suburb areas. Meanwhile, it creates tremendous job opportunities in recycling and AM manufacturing that new residents can start their career.

Over-crowdedness TCI issue caused by over-urbanization and RPR miscontrol can affect the efficiency of recycling as the workforce and facilities cannot be allocated to the location as needed. Furthermore, the overcrowding vagrants and unbalanced population can cause significant damage to sustainability and outbreaks. For this reason, this study proposes golden ratio settings for TCI and RPR metrics control. In general, the control metrics: TCI $<5,000$ and RPR: $15 \%$ - 50\% means golden ratio. It favors sustainability and support sustainable manufacturing.

Through the strategy control model, tremendous recycling and AM manufacturing job opportunities can be created for those unemployed people. It further builds infrastructure for the livelihood of new residents and supports AM HBB communities. Strategy control model focuses on human-centric approaches such as demography, population control, policy, regulations, and management. It produces robust workforce to support $\mathrm{AM}$ and materials recycling in appropriate applications.

\section{REFERENCES}

Alcorta, L. (2015). Industrialization, Employment and the Sustainable Development Agenda. Development 58, 528-539, can be accessed at: https://doi.org/10.1057/s41301-016-0057-6

Alkire, S., Chatterjee, M., Conconi, A., Seth, S., and Vaz, A. (2014). "Poverty in Rural and Urban Areas Direct comparisons using the global MPI 2014“, Oxforf OPHI press

Biermann, F. et al. (2014). Integrating Governance into the Sustainable Development Goals, POST2015/UNU-IAS Policy Brief \#3. Tokyo: United Nations University Institute for the Advanced Study of Sustainability

Chandavarkar, A., (2020), "Wabtec inaugurates Additive Manufacturing Center in Bengaluru", AM Chronicle, can be accessed at: https://www.amchronicle.com/news/wabtec-inaugurates-additive-manufacturing-center-in-bengaluru/

Chowdhury, I. et.al, (2012). Internal Migration and Socio-Economic Status of Migrants: A Study in Sylhet City, Bangladesh, American Journal of Human Ecology Vol. 1, No. 4, 2012, 123-133

City Mayors Statistics, (2018), "Update: 300 largest cities in the world", City Mayors, can be accessed at: http://citymayors.com/statistics/largest-cities-area-250.html

Cotteleer, M., (2014), “3D opportunity for production: Additive manufacturing makes its (business) case”, Deloitte Review (Deloitte Review Issue 15, assessable at: https://www2.deloitte.com/us/en/insights/deloitte-review/issue-15/additive- 
Frost \& Sullivan's Global Research Team, (2016), "Global Additive Manufacturing Market, Forecast to 2025", can be assessed at: https://namic.sg/wp-content/uploads/2018/04/global-additive-manufacturing-market_1.pdf

Gebrea, T., Gebremedhinb, B. (2019). The mutual benefits of promoting rural-urbaninterdependence through linked ecosystem services, Global Ecology and Conservation v.20 can be accessed at:

https://www.sciencedirect.com/science/article/pii/S235198941930143X?via\%3Dihub

Hussain, N., Abdullah1, N., Abdullah H. (2014). "The Relationship between Rural-Urban Migration, Household Income and Unemployment: Malaysia Case Study", International Journal of Managerial Studies and Research, Vol. 2, Issue 8, September 2014, PP 17-24

Kawasaki Eco-town, (2018), "Eco-Town - Current and Future, Ministry of Environment", can be accessed at: https://www.env.go.jp/recycle/ecotown_pamphlet.pdf

McCauley, D. (2008). Sustainable development and the 'governance challenge': the French experience with Natura 2000, Wiley Online Library

Patnaik, R., (2018). Impact of Industrialization on Environment and Sustainable Solutions - Reflections from a South Indian Region, IOP Conf. Series: Earth and Environmental Science 120 (2018) 012016

Ray, I., (2011), "Impact of Population Growth on Environmental Degradation: Case of India", Journal of Economics and Sustainable Development Vol.2, No.8, 2011 pp. 72-78

Serrat, O.(2017). The Sustainable Livelihoods Approach, Knowledge Solutions. Springer, Singapore, can be accessed at: https://doi.org/10.1007/978-981-10-0983-9 5

Shah, M. (2008). Sustainable Development, ScienceDirect Encyclopedia of Ecology

Shaw, R. (2019). Urban Rural Partnership: A Win-Win Solution Towards Resilient Growth, URBANET can be accessed at: https://www.urbanet.info/urban-rural-partnership/

Staub, C., (2019), "Mapping out MRF infrastructure nationwide", can be accessed at: https://resourcerecycling.com/recycling/2019/10/22/mapping-out-mrf-infrastructure-nationwide/Dijkstra, L., (2020), "An emerging global, standard to define cities, urban and rural areas", European Commission, can be accessed at:

https://unstats.un.org/sdgs/files/meetings/iaeg-sdgs-meeting-09/9b.\%20European\%20Commission\%20Rural\%20Disaggregatoin.pdf

Stern, E., (2013), "Demographic sustainability and rural development policy", Journal of Maps, vol. 9-2, pp. 154-160

Strange, T., Bayley, A. (2008). Sustainable Development: Linking economy, society, environment, OECD Publishing

The World Bank, (2020), "Understanding Poverty: Urban Development", can be accessed at: https://www.worldbank.org/en/topic/urbandevelopment/overview

Worldbank, (2018), "Population density", can be accessed at: https://data.worldbank.org/indicator/EN.POP.DNST?end=2018\&start=1997

World Population Review, (2021), "Plastic Pollution By Country 2021", can be accessed at:

https://worldpopulationreview.com/country-rankings/plastic-pollution-by-country

Yeo, J., et al, (2018), "Recent advances in the development of biodegradable PHB-based toughening materials:

Approaches, advantages and applications, Materials Science and Engineering vol 92, pp 1092-1116 